\title{
Extinction Training after Cocaine Self-Administration Induces Glutamatergic Plasticity to Inhibit Cocaine Seeking
}

\author{
Lori A. Knackstedt, ${ }^{1}$ Khaled Moussawi, ${ }^{1}$ Ryan Lalumiere, ${ }^{1}$ Marek Schwendt, ${ }^{1}$ Matthias Klugmann, ${ }^{2}$ \\ and Peter W. Kalivas ${ }^{1}$ \\ ${ }^{1}$ Department of Neurosciences, Medical University of South Carolina, Charleston, South Carolina 29425, and 2Institute of Physiological Chemistry and \\ Pathobiochemistry, University Medical Center of the Johannes Gutenberg University Mainz, 55099 Mainz, Germany
}

Learning to inhibit drug seeking can be an important strategy for inhibiting relapse, and this can be modeled by extinguishing drug seeking in response to a drug-paired context. Rats were either extinguished or withdrawn without extinction training (abstinence) from cocaine self-administration, and measurements of postsynaptic density proteins in the core and shell subcompartments of the nucleus accumbens were compared with yoked-saline controls. Only extinguished rats had elevations of PSD-95, Homer1b/c, and Narp in the postsynaptic density of the core, whereas no proteins measured were altered in the postsynaptic density of the shell in either extinguished or abstinent rats. Using a biotinylation strategy, it was found that surface expression of mGluR5 was reduced only in the core of extinguished animals. Although both extinguished and abstinent animals showed a reduction in long-term potentiation elicited in the core by stimulating prefrontal cortex, blunted long-term depression was observed only in extinguished rats. These data indicate that the elevation in Homer $1 \mathrm{~b} / \mathrm{c}$ in the core may have sequestered mGluR5 away from the membrane surface and that the loss of surface mGluR5 inhibits long-term depression. Accordingly, when Homer $1 \mathrm{c}$ was overexpressed in the core of cocaine-naive rats with an adenoassociated virus, long-term depression was inhibited. This mechanism may contribute to the inhibition of cocaine seeking by extinction training because overexpression of Homer 1c in the core also inhibited cue-induced reinstatement of cocaine seeking. These data identify a cellular mechanism that may contribute to extinction-induced inhibition of cocaine seeking.

\section{Introduction}

Cocaine addiction is a disease characterized by relapse to drug taking, even after long periods of drug abstinence (O'Brien, 2001). One strategy for inhibiting relapse is psychosocial interventions promoting behavioral self-regulation that can include training to extinguish responding to drug-associated environmental stimuli (Conklin and Tiffany, 2002; Havermans and Jansen, 2003). A widely used animal model of relapse is the extinction-reinstatement paradigm. This model combines training animals to self-administer drug with extinction training to inhibit responding in the drug-associated context. Once behavioral responding is inhibited, the drug-seeking response is reinstated with stimuli known to cause relapse in humans, including stress, cues previously associated with drug delivery, and/or the drug itself (Epstein et al., 2006). Using this protocol to model cocaine addiction has revealed enduring neuroplasticity in glutamatergic synapses in the nucleus accumbens (Kauer and Malenka, 2007; Kalivas et al., 2009), a key brain nucleus mediating cocaine seek-

Received March 10, 2010; revised April 19, 2010; accepted April 23, 2010.

This work was supported by National Institutes of Health Grants DA015369, DA012513, DA003906, and DA026010. This work was conducted in a facility constructed with support from National Institutes of Health Grant C06 RR015455.

Correspondence should be addressed to Dr. Lori A. Knackstedt, Department of Neurosciences, Medical University of South Carolina, 173 Ashley Avenue, BSB 403, Charleston, SC 29425. E-mail: knackst@musc.edu.

M. Klugmann's present address: Department of Physiology and Translational Neuroscience Facility, School of Medical Sciences, University of New South Wales, Sydney, NSW 2052, Australia.

DOI:10.1523/JNEUROSCI.1244-10.2010

Copyright $\odot 2010$ the authors $\quad 0270-6474 / 10 / 307984-09 \$ 15.00 / 0$ ing (Koob et al., 2004). However, it remains to be determined which of these adaptations result from cocaine self-administration and which may be associated with the learning and memory consolidation elicited by extinction training (Quirk and Mueller, 2008).

There is reason to suspect that adaptations in the nucleus accumbens may be induced by extinction training. For example, inactivation of the projection from the prefrontal cortex (PFC) to the core compartment of the nucleus accumbens (NAcore) blocks the reinstatement of cocaine seeking in extinguished animals (Cornish et al., 1999; Park et al., 2002; Di Ciano et al., 2008). However, inactivation of neither the prefrontal cortex (Fuchs et al., 2006) nor ventral striatum (See et al., 2007) inhibits relapse in animals undergoing self-administration followed by 2-3 weeks of abstinence without extinction training (referred to herein as "abstinent relapse"), indicating that extinction training may recruit this projection to regulate cocaine seeking. Also, extinction training upregulates GluR1 and/or GluR2 subunits of the AMPA receptor in the shell subcompartment (NAshell) (Sutton et al., 2003; Ghasemzadeh et al., 2009b). Correspondingly, viral overexpression of GluR1 in the NAshell facilitates extinction learning and attenuates reinstated cocaine seeking, whereas overexpression of "pore-dead" GluR1 potentiates cocaine-induced reinstatement (Sutton et al., 2003; Bachtell et al., 2008). Finally, inactivation of the infralimbic PFC projection to the NAshell reverses extinctioninduced inhibition of cocaine seeking (Peters et al., 2008).

Based on these data, it has been proposed that extinction training induces glutamatergic plasticity in the projection from 
the PFC to NAshell that reduces the reinstatement of cocaine seeking (Self et al., 2004; Peters et al., 2009). To expand on this hypothesis, we determined the levels of expression for a number of glutamate receptor and postsynaptic density (PSD) scaffolding proteins in the NAcore and NAshell after cocaine self-administration and 3 weeks of either abstinence or extinction training. Surprisingly, the strongest pattern of extinction training-associated protein changes was in NAcore, not NAshell, and was in part related to mGluR5 and its signaling/scaffolding protein Homer (Xiao et al., 1998; Fagni et al., 2002). Correspondingly, extinction training was shown to inhibit mGluR5-dependent long-term depression (LTD) in the NAcore and Homer1c overexpression inhibited both long-term depression and cue-induced reinstatement of cocaine seeking.

\section{Materials and Methods}

Subjects. Male Sprague Dawley rats (270-300 g at the time of surgery; Charles River) were used in this study. They were individually housed in a temperature-controlled vivarium $\left(22^{\circ} \mathrm{C}\right)$ on a $12 \mathrm{~h}$ light/dark cycle (lights on at 7:00 A.M.) with food and water ad libitum. All methods used were in compliance with National Institutes of Health guidelines for care of laboratory animals and were approved by the Medical University of South Carolina Institutional Animal Care and Use Committee.

Surgery. For the implantation of catheters, rats were anesthetized with ketamine $\mathrm{HCl}(87.5 \mathrm{mg} / \mathrm{kg}$, i.m.) and xylazine ( $5 \mathrm{mg} / \mathrm{kg}$, i.m.). Ketorolac ( $3 \mathrm{mg} / \mathrm{kg}$, i.p.) was administered before surgery to provide analgesia. Catheter construction and surgical implantation has been described in detail previously (Moussawi et al., 2009). For experiments requiring intraaccumbal virus infusions, the catheter implantation was followed immediately sterotaxic implantation of guide cannula over the NAcore (anteroposterior, $\pm 1.7 \mathrm{~mm}$; mediolateral, $\pm 2.5 \mathrm{~mm}$ at $6^{\circ}$ angle; dorsoventral, $-5.5 \mathrm{~mm}$ ) (Paxinos and Watson, 1986). Rats were allowed to recover 6-10 $\mathrm{d}$ after surgery before the start of the experimental protocol.

Cocaine self-administration, extinction, and abstinence procedures. All self-administration procedures occurred in standard operant chambers with two retractable levers, a house light, a cue light, and tone generator (MED Associates). Before the initiation of cocaine self-administration training, all animals were food deprived for $24 \mathrm{~h}$ and then underwent a single $15 \mathrm{~h}$ session in which presses on the active lever (the right lever) resulted in the delivery of a single food pellet ( $45 \mathrm{mg}$; Noyes). Subsequent to food training, animals were food restricted for the remainder of the experiment and were given $20 \mathrm{~g}$ of food immediately after each daily drug self-administration session. One day later, subjects $(n=114)$ began cocaine self-administration on an FR1 schedule with a 20 s time-out. Active lever presses made during the time-out were recorded but did not result in drug delivery. Each active lever press produced a $0.05 \mathrm{ml}$ infusion of $0.20 \mathrm{mg}$ of cocaine (dissolved in $0.9 \%$ sterile saline; kindly provided by National Institute on Drug Abuse) and the presentation of drug-paired cues (illumination of the light over the active lever and the presentation of a $2900 \mathrm{~Hz}$ tone). A subset of animals $(n=73)$ served as yoked-saline controls and received a saline infusion each time their cocaine counterpart received a cocaine infusion. Each cocaine self-session lasted $2 \mathrm{~h}$ or until the rats had taken a maximum of 200 infusions. Self-administration continued until subjects had attained $12 \mathrm{~d}$ with a minimum of 10 cocaine infusions. Subjects then were divided into two groups: one group undergoing extinction training and another undergoing home cage abstinence. During extinction training, presses on the previously active lever were recorded but no longer produced drug or presentation of the drug-paired cues. Animals in the abstinence group remained in their home cages with the exception of a $2 \mathrm{~h}$ period during which they were removed and placed into an alternative environment (standard housing Plexiglas cage) to control for the effects of handling and daily removal from the home environment. Extinction or abstinence procedures continued for 3 weeks, at which point animals were decapitated and NAcore and NAshell tissue was dissected. In a subset of animals $(n=18)$, extinction training only lasted for $2 \mathrm{~d}$ and animals were decapitated $24 \mathrm{~h}$ after the last extinction session.
Food self-administration procedures. To control for the general effect of extinction training, one group of animals $(n=9)$ self-administered sucrose pellets for $12 \mathrm{~d}$ and then underwent 3 weeks of extinction training. Control animals $(n=9)$ were placed in the self-administration chambers daily but did not receive food reinforcement.

Subfractionation and Western blotting methods. Dissected NAshell and NAcore were homogenized in sucrose buffer containing protease inhibitors. After spinning at $1000 \times g$, the supernatant was retrieved and spun at $12,000 \times g$. The resulting pellet was resuspended in $1 \mathrm{~mm}$ EDTA, $4 \mathrm{~mm}$ HEPES, and protease inhibitors, and spun at $12,000 \times g$. The supernatant was discarded and the pellet was resuspended in $0.5 \%$ Triton X in PBS and spun at $12,000 \times g$. The resulting pellet contained the PSD (Triton $\mathrm{X}$-insoluble) fraction, and the supernatant was retained as the nonpostsynaptic membrane fraction (non-PSD) (Triton X-soluble). The pellet containing the PSD fraction was suspended in 1\% SDS in radioimmunoprecipitation assay buffer. Protein content was measured using the Bradford assay, and two samples were pooled to generate sufficient tissue for immunoblotting. Proteins were separated using 10\% SDS-PAGE and transferred to polyvinylidene difluoride membrane. The membranes were blocked in $3 \%$ milk and probed overnight at $4^{\circ} \mathrm{C}$ with primary antibody against GluR1 (1:200; Millipore Bioscience Research Reagents), washed with TBS-Tween, and incubated with secondary antibody at room temperature. After visualization (Pierce Western Mouse Pico kit) of GluR1, membranes were reprobed with Homer1b/c antibody (1:5000; Millipore Bioscience Research Reagents), then neuronal activity regulated pentraxin (NARP) (1:3000; Paul Worley, Baltimore, MD), and subsequently with PSD-95 (1:2500; Sigma-Aldrich). Separate sets of membranes was used to probe for GluR2 (1:300; BD Biosciences), mGluR1 (1:1000; Millipore), mGluR5 (1:20,000; Millipore), and mGluR2/3 (1:5000; Millipore). Both mGluR1 and mGluR5 are present in monomer and dimer forms, and we report dimer expression because this is the active form of group I mGluRs (Pin et al., 2003; Kniazeff et al., 2004; Tateyama et al., 2004). Figure $1 B$ illustrates the relative capacity of this subfractionation procedure to separate PSD from non-PSD proteins.

Biochemical measurement of surface-expressed mGluR5. A subset of animals that underwent cocaine self-administration and either 3 weeks of extinction training $(n=9)$ or abstinence $(n=7)$ and their yoked-saline counterparts (extinction controls, $n=9$; abstinence controls, $n=7$ ) were killed via rapid decapitation. The NAcore was dissected and sliced into prism-shaped sections $(200 \mu \mathrm{m})$ with a Mcllwain tissue chopper. The tissue was incubated for $1 \mathrm{~h}$ in artificial CSF (aCSF) containing 1 $\mathrm{mg} / \mathrm{ml}$ sulfo-NHS-SS-biotin (Pierce) at $4^{\circ} \mathrm{C}$ with gentle shaking. Unreacted biotinylation reagent was removed by two $10 \mathrm{~min}$ washes in icecold aCSF and quenched by two 20 min washes in ice-cold aCSF containing $100 \mathrm{~mm}$ glycine. The sections were then homogenized by sonication in $150 \mu \mathrm{l}$ of lysis buffer containing $25 \mathrm{~mm}$ HEPES, $150 \mathrm{~mm}$ $\mathrm{NaCl}, 1 \%$ Triton X-100, and Complete Mini protease inhibitors (Roche). Homogenates were subsequently centrifuged $\left(10,000 \times g\right.$ at $4^{\circ} \mathrm{C}$ for 10 $\mathrm{min}$ ) to remove insoluble material. A total of $250 \mu \mathrm{g}$ of each sample lysate was incubated overnight at $4^{\circ} \mathrm{C}$ with $50 \mu \mathrm{l}$ of streptavidin agarose beads (Sigma-Aldrich) and the remainder of the sample was stored at $-80^{\circ} \mathrm{C}$ as the total protein fraction $(\mathrm{T})$. Biotinylated proteins attached to streptavidin-coated beads were separated by centrifugation from the nonbiotinylated proteins (NB) in the supernatant. The beads were washed three times at $4^{\circ} \mathrm{C}$ in lysis buffer and once in $50 \mathrm{~mm}$ Tris- $\mathrm{HCl}, \mathrm{pH}$ 7.4. Biotinylated proteins (B) were eluted with Laemmli sample buffer containing $100 \mathrm{~mm}$ dithiothreitol. The amount of mGluR5 protein in the total and biotinylation fractions was analyzed by quantitative Western blotting using anti-mGluR5.

Electrophysiological recordings. Extracellular field potentials were recorded after $2-3$ weeks of extinction $(n=7)$ or abstinence $(n=11)$ in urethane-anesthetized rats that were mounted in a stereotaxic apparatus. Detailed methods describing this experiment have been published previously (Moussawi et al., 2009). Data were collected every $30 \mathrm{~s}$ at a $10 \mathrm{kHz}$ sampling frequency, and then averaged every $1 \mathrm{~min}$. Pulse width was set to $0.3 \mathrm{~ms}$ and basal stimulation intensity corresponded to $30-40 \%$ of minimum current intensity that evoked a maximum field response for long-term potentiation (LTP) experiments, and $40-50 \%$ for LTD exper- 
iments. Baseline data were collected for 20-30 min before the induction protocol (LTP or LTD). Field potential amplitude was measured as the difference between the mean of a 2-4 ms window before the stimulation artifact and the mean of a $1 \mathrm{~ms}$ window around $15 \mathrm{~ms}$ after the stimulation artifact (corresponding to the negative peak of the field potential). Data were then normalized to baseline. The LTP protocol involved tetanic stimulation at the minimum current intensity that evoked a maximum field response (from an input-output curve) using two bursts of 100 pulses at $50 \mathrm{~Hz}(2 \mathrm{~s})$, with $20 \mathrm{~s}$ interburst interval. The LTD protocol involved stimulation at the minimum current intensity that evoked a maximum response using three trains of 900 pulses at $5 \mathrm{~Hz}(3 \mathrm{~min})$, with a 5 min intertrain interval.

Homer1c overexpression. Recombinant adenoassociated viral vectors with equal ratios of serotype 1 and 2 capsid proteins (rAAV1/2) carrying the cDNA for full-length hemagglutinin (HA)-tagged rat Homerlc $(n=18)$ or enhanced green fluorescent protein (GFP) $(n=16)$ as a control were constructed and infused into the NAcore as described previously (Szumlinski et al., 2006). AAV1/2 vectors specifically transduce neurons (Klugmann et al., 2005) and transgene expression is controlled by the strong CBA (chicken- $\beta$-actin) promoter. For the measurement of long-term depression, five animals were infused with adenoassociated virus (AAV) vectors 2 weeks before electrophysiolgical recording. For the reinstatement experiment, microinjections occurred $24 \mathrm{~h}$ after the final self-administration session and animals either began extinction training on the day after the viral infusion ( $n=$ 21) or experienced abstinence in the home cage for 2 weeks before beginning extinction training $(n=13)$. Animals in both groups underwent extinction training for a minimum of 2 weeks or until the extinction criterion was achieved ( $25 \%$ of active lever pressing during self-administration), and cue-induced reinstatement tests were conducted during which the cues previously paired with cocaine (light plus tone) were again presented on active lever pressing. Responses on the previously active lever were recorded but did not result in drug infusions. For the measurement of LTD, five cocaine-naive animals were injected with Homer1c or GFP AAV into the contralateral NAcore as described above. Two to 3 weeks later, the rats underwent the induction of LTD as described above by recording at the AAV infusion site and stimulating the prelimbic region of the prefrontal cortex. Each hemisphere of the brain was examined for the induction of LTD, with the Homer1c side examined first in three of the five animals.

Histology. Rats were overdosed with sodium pentobarbital $(100 \mathrm{mg} /$ $\mathrm{kg}$, i.p.) and intracardially perfused with $0.9 \%$ saline. The brains were removed and stored in $10 \%$ formalin for at least $24 \mathrm{~h}$. Coronal sections (150 $\mu \mathrm{m}$ thick) were mounted on slides and stained with cresyl violet. Sites of injector needles or recording electrodes were verified with a light microscope. To verify overexpression of Homer AAV, slides were incubated with mouse anti-HA primary antibody (Covance; 1:1000), and labeled proteins were detected using a biotinylated anti-mouse $\operatorname{Ig} G$ and visualized with diaminobenzidine (Szumlinski et al., 2006).

D NAcore
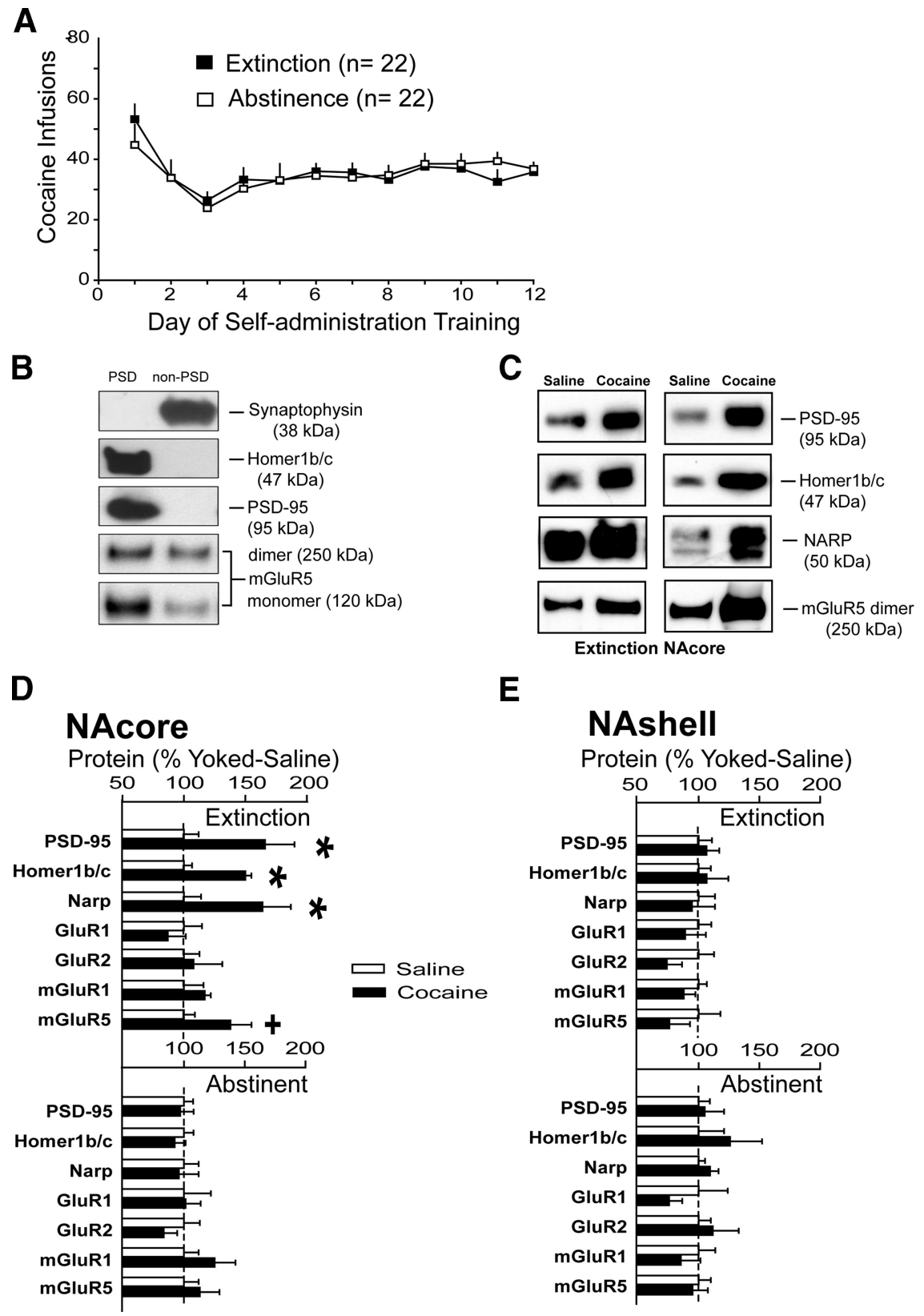

$\mathbf{E}$

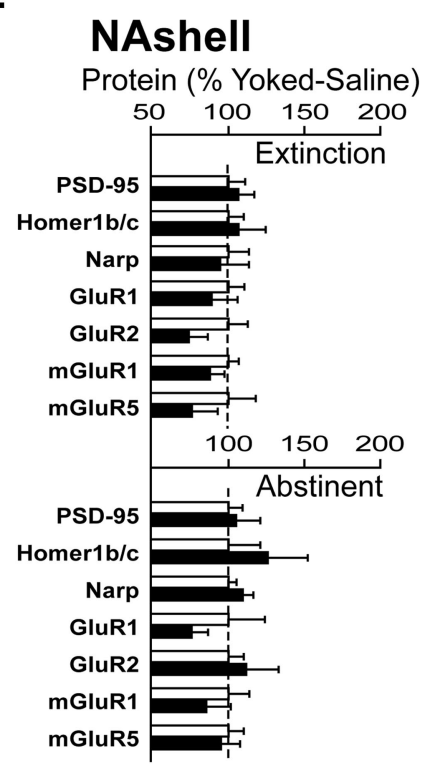

Figure 1. Extinction training $(E x)$ and abstinence $(A b)$ after cocaine self-administration produced different patterns of changes in protein expression in the PSD-enriched fraction. $A$, The mean number of infusions did not differ between $A b$ and Ex groups. $\boldsymbol{B}$, Representative Western blots demonstrating the composition of PSD and non-PSD fractions based on the presence of characteristic proteins. $C$, Sample Western blots showing protein upregulation in the Ex group. D, NAcore PSD-enriched fraction protein expression. Two-tailed Student's $t$ test revealed that PSD-95 $\left(t_{(13)}=2.50 ; p=0.027\right)$, Homer1b/c $\left(t_{(15)}=3.15 ; p=0.007\right)$, NARP $\left(t_{(14)}=2.22 ; p=0.043\right)$, and mGluR5 $\left(t_{(20)}=2.00 ; p=0.059\right)$ were increased after extinction training but not abstinence. $\boldsymbol{E}$, Nucleus accumbens shell PSD-enriched fraction protein expression showed no differences after extinction training or abstinence. $N=6-12$ for all groups. ${ }^{*} p<0.05 ;{ }^{+} 0.05>p<$ sion showed no differences a
0.06 . Error bars indicate SEM.

\section{Results}

Increased protein expression in NAcore after extinction training but not abstinence

Animals underwent 2 weeks of cocaine self-administration and 3 weeks of either extinction training or abstinence in the home cage with daily handling. Control animals received saline infusions when their yoked cocaine counterpart self-administered cocaine. Akin to treatment animals, yoked control animals were divided into abstinent and extinction treatment groups. Figure $1 \mathrm{~A}$ shows 


\section{A NAcore}

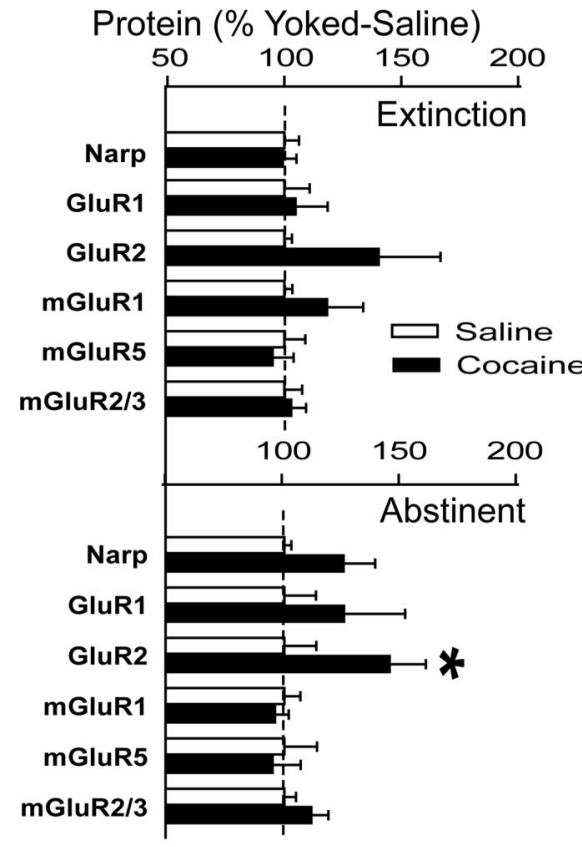

\section{B NAshell}

Protein (\% Yoked-Saline)

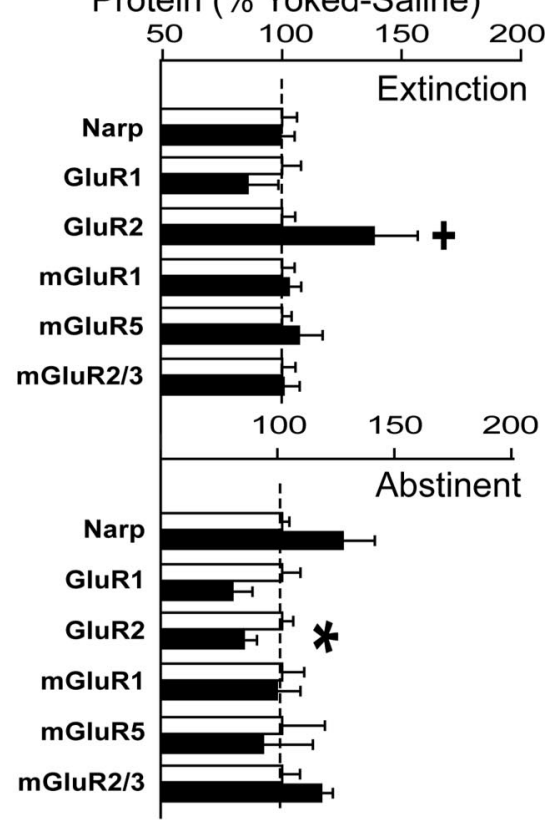

C

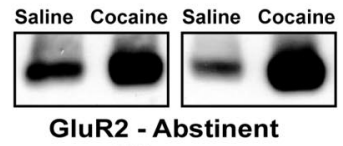

GluR2 - Abstinent NAcore

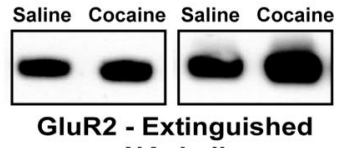

NAshell

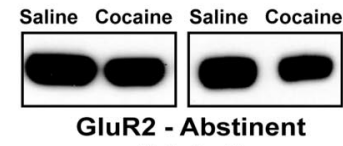

NAshell

Figure 2. Extinction training and abstinence after cocaine self-administration produced different patterns of changes in protein expression in the non-PSD subfraction (Triton X-100-soluble fraction). $\boldsymbol{A}$, No change was measured in the NAcore in extinguished subjects, whereas changes after abstinence were observed in levels of GluR2 $\left(t_{(12)}=2.18 ; p=0.050\right)$. $\boldsymbol{B}$, In the NAshell non-PSD fraction, GluR2 ( $t_{(11)}=2.13 ; p=0.057$ ) was changed in extinguished animals, and in abstinent animals changes were measured in GluR2 ( $\left.t_{(12)}=2.38 ; p=0.035\right) . N=6-12$ for all groups. C, Representative immunoblots of significant changes in protein level. ${ }^{*} p<0.05 ;{ }^{+} 0.05>p<0.06$. Error bars indicate SEM.

no differences in the mean number of cocaine infusions selfadministered by the abstinent and extinction groups (active lever presses are not shown but were not different between groups). Stable amounts of extinguished active lever pressing were achieved within 1 week of training, in rats undergoing extinction training (data not shown). Figure 1, $C$ and $D$, shows that, although no changes were measured in the PSD-enriched subfraction of the NAcore in abstinent subjects, expression of PSD-95, Homer1b/c, and Narp were increased in cocaine animals after extinction training. In addition, mGluR5 showed a trend toward an increase $(p<0.06)$.

In contrast to the changes observed in the NAcore after extinction training, there was no change in NAshell PSD protein expression in either the abstinent or extinction groups (Fig. $1 E$ ). In the non-PSD fraction (Triton X-100-soluble fraction), Figure $2 \mathrm{~A}$ reveals only GluR2 expression was increased in the NAcore of cocaine self-administering animals after abstinence. Figure $2 B$ shows a trend $(p<0.06)$ toward increased GluR2 in extinguished subjects and reduced GluR2 in the non-PSD subfraction of the NAshell in abstinent animals.

Control extinction protocols do not affect protein expression To ensure that the increase in glutamatergic protein expression in the PSD-enriched fraction of the NAcore (Fig. $1 D$ ) was not a consequence of extinction training regardless of the original learned response, a group of animals was trained to self- administer sucrose pellets. Figure 3 shows that animals rapidly extinguished their responding on the previously active lever, and after 3 weeks of extinction from sucrose self-administration, the expression of PSD-95, Homer1b/c, NARP, and mGluR5 was unchanged relative to control rats in the PSD subfraction of the NAcore (Fig. 3B). To investigate the amount of post-cocaine extinction training necessary to elicit the protein upregulation, we examined animals with only $2 \mathrm{~d}$ of extinction training after 2 weeks of cocaine selfadministration (Fig. 3C). After $2 \mathrm{~d}$ of extinction training, the levels of PSD-95, Homer1b/c, Narp, and mGluR5 were unchanged in the PSD fraction of the NAcore (Fig. 3D) or NAshell (data not shown). Thus, the protein upregulation elicited in the NAcore after 3 weeks of extinction from cocaine self-administration was not a consequence of either cocaine selfadministration or extinction learning alone, but rather a combination of these two training procedures.

\section{Extinction training alters the surface expression of mGluR 5}

Given that one function of Homer $1 \mathrm{~b} / \mathrm{c}$ is the reduction of mGluR1/5 membrane surface expression through intracellular retention (Fagni et al., 2002; Kammermeier, 2006), we hypothesized that the upregulated Homer1b/c (Fig. 1D) promotes the internalization and sequestering of mGluR5 into the PSD subfraction, thereby accounting for both the loss of LTD (Moussawi et al., 2009) and increase in PSD levels of mGluR5 (Xiao et al., 1998; Fagni et al., 2002). To examine this possibility, a biotinylation strategy was used to measure the surface expression of mGluR5 in the NAcore after 3 weeks of extinction training or abstinence in rats trained to self-administer cocaine. Figure 4 shows that the surface expression of mGluR5 dimer was reduced after extinction training, but not abstinence, supporting the hypothesis that upregulated Homer1b/c in the NAcore after extinction training serves to internalize and sequester mGluR5 in the PSD.

Extinction training is required for cocaine-induced loss of long-term depression

Two well characterized forms of neuroplasticity at glutamatergic synapses in the CNS are LTP and LTD (Malenka and Bear, 2004), and the proteins found to be upregulated in the NAcore by extinction training have been linked to LTP and/or LTD. Narp multimerizes with neuronal pentraxin 1 to promote clustering of AMPA receptors and synaptogenesis (Xu et al., 2003). Since AMPA receptor clustering promotes LTP (Andrásfalvy and Magee, 2004) and Narp mRNA has been shown to be upregulated after LTP induction (Wibrand et al., 2006), it follows that upregulating Narp by extinction training might lead to enhanced LTP. Conversely, targeted disruption of PSD-95 in the hippocampus enhances LTP induction (Migaud et al., 1998) and nucleus accumbens LTP is augmented as a consequence of re- 
duced PSD-95 levels (Yao et al., 2004), supporting a reduction in LTP by the upregulated PSD-95 in extinguished animals. The changes in PSD proteins also provide a mixed expectation regarding LTD. Homer1b/c binds mGluR5 and can thereby promote either retention of mGluR 5 on the surface or internalization, depending on the in vitro experimental conditions (Xiao et al., 1998; Fagni et al., 2002). Endocannabinoid-mediated LTD in the accumbens is mGluR5 dependent (Robbe et al., 2002). Accordingly, surface retention or internalization of mGluR5 via increased Homerlb/c binding would be expected to promote or inhibit LTD, respectively.

Impaired LTP and LTD was recently recorded in field potentials measured in the NAcore after prefrontal cortex stimulation in animals extinguished from cocaine self-administration (Moussawi et al., 2009). Using this model, we compared animals undergoing extinction training or abstinence from 2 weeks of cocaine selfadministration for the capacity to induce LTP and LTD in the NAcore. Figure $5 A$ shows that LTP was impaired in both extinguished and abstinent animals. However, LTD was impaired only after extinction training (Fig. 5B). This implies that the selective upregulation in Narp and PSD-95 in the NAcore of extinguished animals does not confer differences in the ability to induce LTP. However, upregulation of Homerlb/c and internalization of mGluR5 after extinction training may be linked to a loss of LTD. To verify this hypothesis, we used an AAV infection strategy to induce bilateral overexpression of HA-tagged Homerlc in the NAcore of cocaine-naive animals and measured LTD (for an example of Homer1c-overexpressing neurons in the NAcore, see Fig. 6E). We found that Homerlc overexpression impaired the induction of LTD by low-frequency stimulation, indicating that, in extinguished animals, the increase of Homerlb/c expression could be mediating the reduced capacity to induce LTD.

\section{Overexpression of Homer $1 \mathrm{~b} / \mathrm{c}$ in the NAcore inhibits cue- induced reinstatement}

Upregulating Homer $1 \mathrm{~b} / \mathrm{c}$ and reducing the surface expression of mGluR5 and ability to induce LTD could be either a pathologic consequence of cocaine self-administration and extinction training or a compensatory mechanism serving to reduce additional cocaine seeking. Based on literature showing that virally mediated overexpression of Homer1 long forms prevents behavioral sensitization induced by chronic cocaine (Szumlinski et al., 2006) and that Homerl gene deletion produces a cocaine-sensitized phenotype (Szumlinski et al., 2004), we predicted that overex-
B
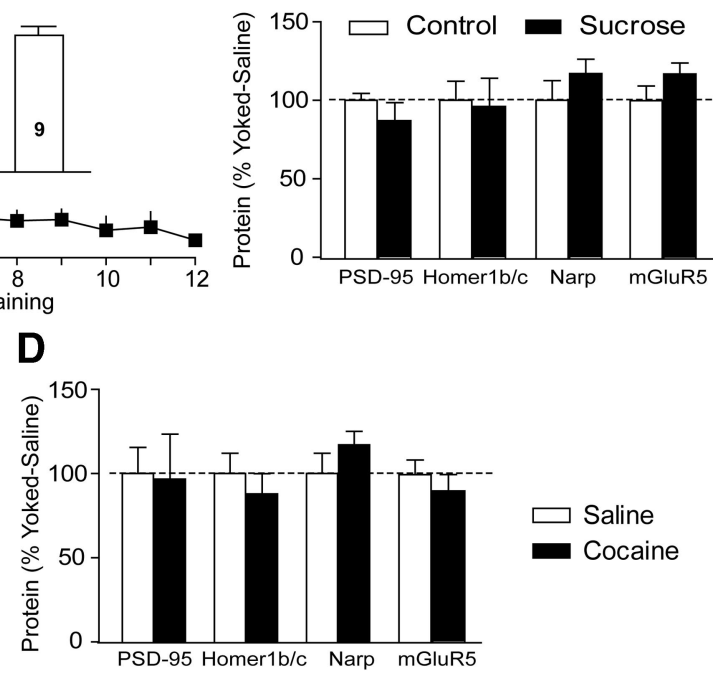

Figure 3. Extinction-associated changes in protein require both extinction training and cocaine self-administration. $A$, Mean active lever responses during the first $12 \mathrm{~d}$ of extinction training after sucrose pellet self-administration. Inset, Total number of sucre pellets earned during self-administration training. $N=9$. $\boldsymbol{B}$, There were no changes in protein expression of PSD-95, lever responses during the $2 \mathrm{~d}$ after cocaine self-administration. Inset, Total number of cocaine infusions earned during expression of PSD-95, Homer1b/c, and NARP after $2 \mathrm{~d}$ of extinction training of cocaine-reinforced responding. $N=6-12$ in each
A Extinguished

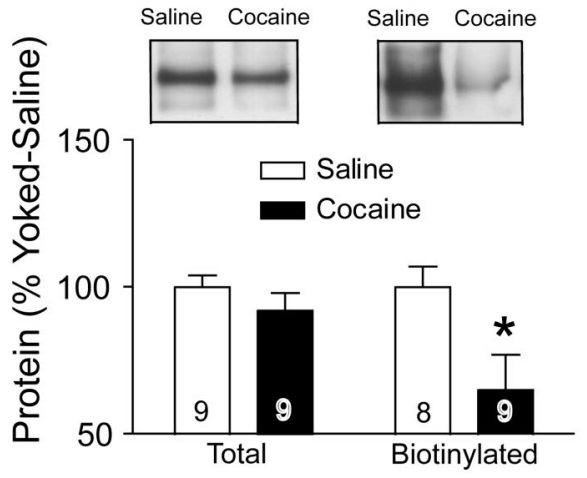

B Abstinent

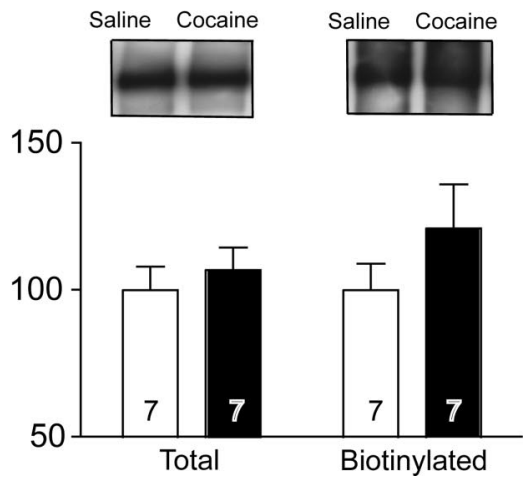

Figure 4. Surface expression of mGluR5 is reduced after extinction training but not abstinence from cocaine selfadministration. $\boldsymbol{A}$, Surface expression of mGluR5 was significantly decreased after cocaine self-administration and 3 weeks of extinction $\left(t_{(1,14)}=3.31 ; p=0.006\right)$, whereas expression was unaltered in a whole-cell fraction. $\boldsymbol{B}$, Surface expression of $m G l u R 5$ was not altered after abstinence from cocaine self-administration. $N$ is shown in bars. Error bars indicate $S E M$.

pression of Homerlc would attenuate the reinstatement of cocaine seeking. We infused Homerlc AAV into the NAcore after cocaine self-administration. Figure $6 E$ shows that this procedure induced robust and localized expression of HA-tagged Homer1c in soma and fibers selectively in the NAcore. This AAV requires 2 weeks to achieve maximum expression (Szumlinski et al., 2006), allowing us to examine two conditions of Homer1c overexpression: first, virus infusion followed immediately by 3 weeks of extinction training (Fig. 6A,C), and second, virus infusion followed by a 2 week abstinence period before initiating extinction training (Fig. $6 B, D$ ). Using either protocol, there was no effect of Homerlc overexpression on extinction responding compared with animals bilaterally infected in the NAcore with GFP control 

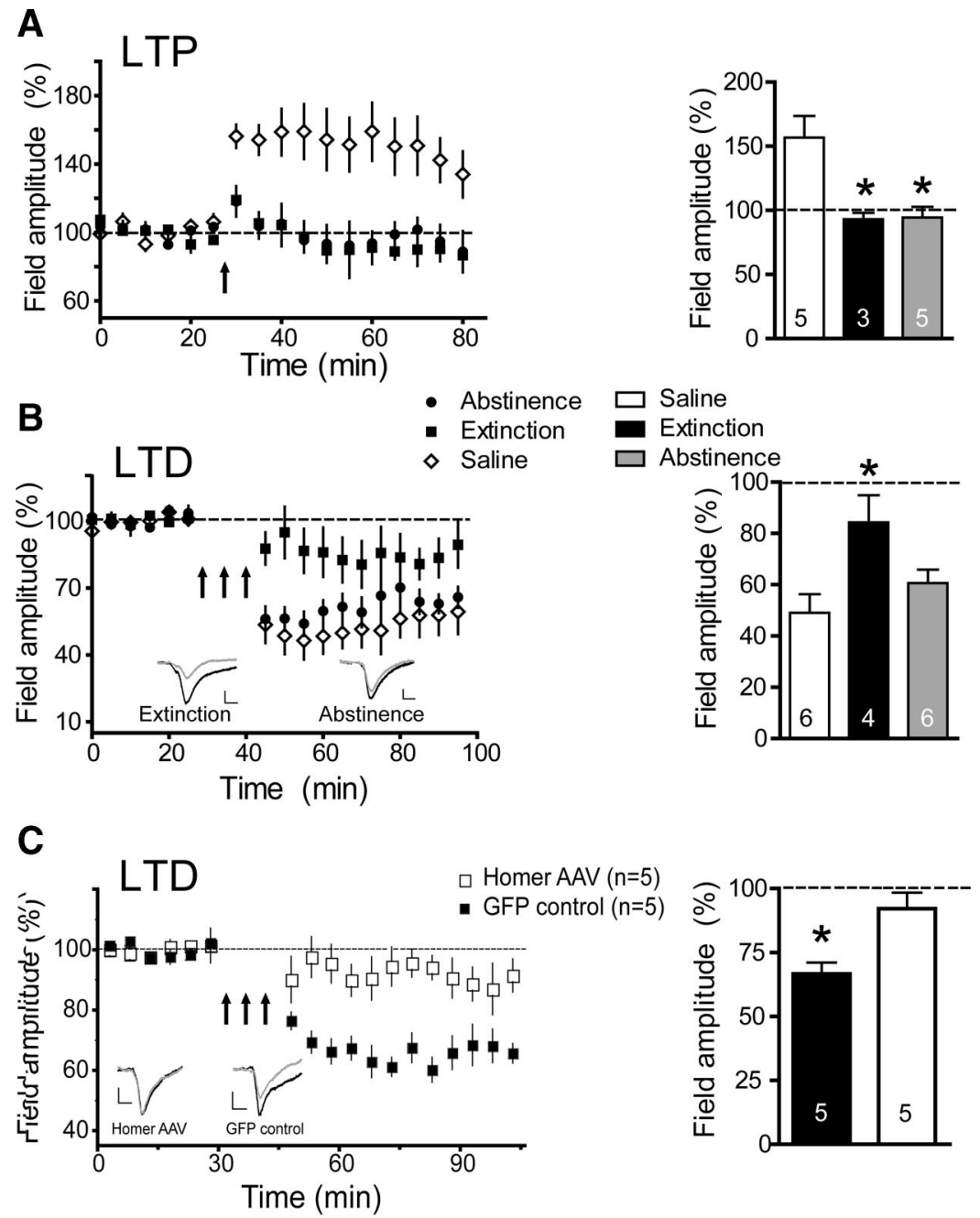

Figure 5. Extinction training inhibits the induction of LTD in the NAcore elicited by PFC stimulation. $A$, Rats trained to selfadminister cocaine show blunted LTP regardless of abstinence or extinction training (time, $F_{(16,32)}=36.94, p<0.001$; treatment, $F_{(2,32)}=4.67, p=0.030$; interaction, $\left.F_{(32,208)}=3.24, p<0.001\right)$. The right panel shows the average field amplitude measured between 15 and 30 min after high-frequency stimulation $\left(F_{(2,12)}=8.30 ; p=0.008\right) . B$, Only rats extinguished from cocaine self-administration show blunted LTD (time, $F_{(16,32)}=5.26, p<0.001$; treatment, $F_{(2,32)}=8.90, p=0.006$; interaction, $\left.F_{(32,160)}=5.63, p<0.001\right)$. The right panel shows the average field amplitude measured between 15 and 30 min after lowfrequency stimulation $\left(F_{(2,13)}=5.22 ; p=0.022\right)$. C, When Homer 1 c was overexpressed in the NAcore of cocaine-naive animals, LTD was blunted relative to GFP-infused controls (time, $F_{(17,136)}=13.37, p<0.001$; treatment, $F_{(1,136)}=17.49, p=0.003$; interaction, $\left.F_{(17,136)}=5.658, p<0.001\right)$. The right panel shows the average field amplitude measured between 15 and 30 min after low-frequency stimulation $\left(t_{(1,9)}=17.483 ; p=0.003\right)$. $N$ is shown in bars. ${ }^{*} p<0.05$, using Dunnett's $t$ test to compare extinction and abstinent groups to yoked-saline. Error bars indicate SEM.

virus (Fig. 6A,B). Notably, in the experiment in which a 2 week abstinence phase was imposed before the initiation of extinction training, exposure to the operant chamber on the first day of extinction served as an abstinent-relapse test in the presence of full Homer1c overexpression. The lack of difference between GFP- and Homer1c-infected animals on day 1 of extinction in Figure $6 B$ revealed that Homer1c overexpression in the NAcore did not inhibit abstinent relapse. In contrast, Figure 6, $C$ and $D$, reveals that, when using either infection protocol, Homer1c overexpression attenuated cue-induced reinstatement of cocaine seeking.

\section{Discussion}

Extinction training and abstinence after cocaine self-administration produced different patterns of protein expression in the NAcore and NAshell. Notably, extinction training upregu- lated the level of proteins that modulate the expression and clustering of glutamate receptors in the $\mathrm{PSD}$, including PSD-95, Narp, and Homer1b/c. The extinction-induced increase in Homer $1 \mathrm{~b} / \mathrm{c}$ was associated with enhanced internalization and sequestering of mGluR5 in the PSD subfraction, which likely accounted for the selective loss of mGluR5dependent LTD in the extinguished, but not abstinent animals. Supporting this connection, overexpression of Homer1c promotes intracellular retention of mGluR5 (Kammermeier, 2006) and resulted in a loss of the ability to elicit LTD in the NAcore and also inhibited cue-induced reinstatement.

\section{Altered protein expression in the NAcore by extinction training inhibits reinstatement}

The possibility that upregulated Homer1b/c in the NAcore may be a neuroadaptation produced by extinction training to inhibit cocaine seeking is consistent with the literature. Other than the immediate-early gene-like product Homerla, all forms of Homer are constitutively expressed in the PSD and possess a coiled-coil motif at the $\mathrm{C}$ terminal that permits multimerization between Homer proteins and mGluR1/5, forming a signaling and trafficking complex (Xiao et al., 1998; Fagni et al., 2002). The interaction with Homer1b/c includes reducing mGluR1/5 membrane surface expression through intracellular retention (Fagni et al., 2002; Kammermeier, 2006). Accordingly, we found that mGluR5 surface expression was reduced in the presence of extinction training-induced increases in Homer1b/c. The fact that mGluR5 levels were also marginally increased (Fig. $1 D$ ) indicated not only internalization, but sequestration of the receptor in the PSD subfraction. Ghasemzadeh et al. (2009a) reported no change in mGluR5 monomer subunit expression after extinction and an increase after abstinence; however, the dimer is the active form of the receptor (Pin et al., 2003; Kniazeff et al., 2004; Tateyama et al., 2004).

The reduced surface expression of mGluR5 in extinguished animals was associated with a loss of LTD and is consistent with the mGluR5-dependent LTD shown previously in the nucleus accumbens (Robbe et al., 2002; Moussawi et al., 2009). Moreover, inhibition of mGluR5 binding to Homer proteins prevents mGluR5-dependent LTD in the hippocampus (Ronesi and Huber, 2008). Also, a loss of mGluR5-dependent LTD in the accumbens after a single noncontingent injection of cocaine is accompanied by an increase in the expression of long-form Homer proteins (which includes Homer1b/c), and decreased surface expression of mGluR5 (Fourgeaud et al., 2004). The preservation of LTD in abstinent animals contrasts a previous study showing a loss of LTD in the NAcore after $21 \mathrm{~d}$ of abstinence in rats trained to self-administer cocaine (Martin et al., 2006). Ex- 
planations for this discrepancy include the fact that Martin et al. conducted in vitro whole-cell recordings while we measured in vivo field potentials. In vivo recordings permit selective stimulation of PFC afferents into the NAcore, whereas in vitro electrical stimulation may activate multiple glutamatergic afferents to accumbens spiny cells. Supporting stimulating multiple afferents as a potentially important distinction, withdrawal from noncontingent chronic cocaine administration differentially alters the capacity of in vivo hippocampal versus prefrontal cortex stimulation to induce LTP or LTD in the NAshell (Goto and Grace, 2005).

The present data indicate that the upregulated Homer1b/c-induced internalization of mGluR5 and loss of LTD may contribute to the inhibition of cocaine seeking produced by extinction training. Thus, overexpression of Homer 1c in the NAcore inhibited cue-induced reinstatement in extinguished animals but did not alter abstinent relapse. Previous studies also show that Homer1 negatively regulates cocaine reward learning and behavioral plasticity. Homerl gene deletion predisposes mice to cocaine conditioned place preference and locomotor sensitization (Szumlinski et al., 2004), and viral overexpression of Homer1c in the accumbens prevents both locomotor sensitization and the reductions in extracellular glutamate in the NAcore elicited by chronic noncontingent cocaine administration (Szumlinski et al., 2006). In addition, mGluR5 regulates the expression of cocaine behavior and the development of behavioral plasticity to chronic cocaine in a manner consistent with the reduction in surface expression of mGluR5 observed in the present study. For example, constitutive deletion of the mGluR5 gene renders mice incapable of developing cocaine-induced locomotor sensitization or reward learning (Chiamulera et al., 2001), and pharmacological antagonism of mGluR5 attenuates cue- and cocaine-induced reinstatement of drug seeking (Bäckström and Hyytiä, 2006; Kumaresan et al., 2009). Conversely, glutamatergic tone on mGluR5 in the accumbens is reduced after chronic cocaine administration because of downregulated cystine-glutamate exchange (Madayag et al., 2007; Moussawi et al., 2009), and restoring glutamatergic tone onto mGluR5 with $\mathrm{N}$-acetylcysteine after withdrawal from cocaine selfadministration not only potentiates cocaine-induced reinstatement in the presence of an allosteric mGluR5 agonist but also restores the capacity to induce LTD in the NAcore (Moussawi et al., 2009). Considered together, the present and previous studies support a conclusion that extinction training is upregulating Homer $1 \mathrm{~b} / \mathrm{c}$ levels in the NAcore causing internalization of mGluR5 and loss of LTD, thereby inhibiting cocaine seeking.

Although the loss of the ability to elicit LTD in the NAcore can be induced by increasing Homer1c expression (Fig. 5C), it 1984). Error bars indicate SEM.

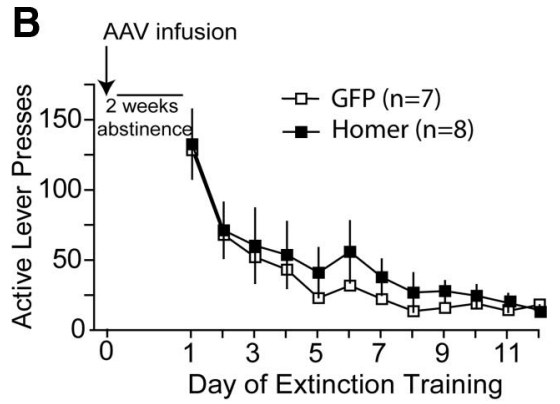

D
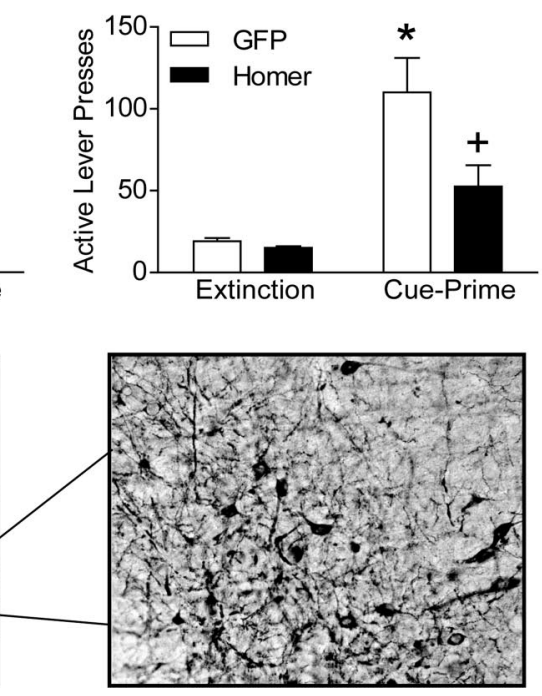

Figure 6. Overexpression of Homer1c in the NAcore attenuated reinstatement of cocaine seeking. $\boldsymbol{A}$, There was no difference in extinction learning between Homer1c-AAV- and GFP-AAV-infected animals when the AAVs were administered $1 \mathrm{~d}$ before the initiation of extinction training. $\boldsymbol{B}$, There was no difference in extinction learning between Homer1c- and GFP-infected animals

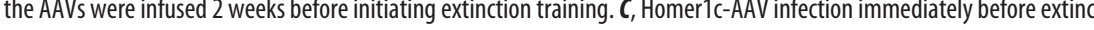
cue-prime) confirms significant main effects of virus $\left(F_{(1,18)}=5.68 ; p=0.028\right)$ and trial $\left(F_{(1.18)}=20.00 ; p<0.001\right)$, as well as 28.90; $p<0.001)$, as well as a significant interaction $\left(F_{(1,13)}=6.37 ; p=0.025\right)$. $\boldsymbol{E}$, Immune staining of HA-tagged

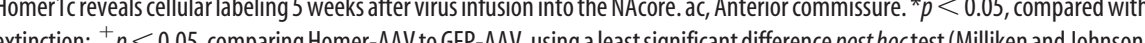

is possible that the loss of LTD is an epiphenomenon of decreased mGluR5 surface expression that is unrelated to the attenuation of reinstatement. Stimulation of mGluR5 receptors in the accumbens has many intracellular consequences in addition to being essential for the induction of mGluR5-dependent LTD. For example, mGluR5 stimulation leads to the appearance of NMDA receptor-dependent slow inward currents in medium spiny neurons (D'Ascenzo et al., 2007), increased ERK (extracellular signalregulated kinase) activation (Mao et al., 2005), and increased phosphorylation of protein kinase $\mathrm{C} \varepsilon$ (Olive et al., 2005). Thus, the loss of LTD is just one of many possible mechanisms by which decreased mGluR5 signaling in the accumbens could lead to attenuated reinstatement of cocaine seeking. However, preventing the induction of LTD in the nucleus accumbens has been shown to prevent the expression of behavioral sensitization to amphetamine (Brebner et al., 2005), indicating that there are addiction-related behaviors that are directly related to the ability to induce LTD.

The fact that both abstinent and extinguished animals demonstrated loss of LTP indicates that the extinction-selective 
changes in protein expression are not significant mediators of LTP. The increase in PSD-95 after extinction training has been observed previously in NAcore whole-cell lysates (Ghasemzadeh et al., 2009b); however, in the same extinguished animals, neither Homer1b/c nor PSD-95 were upregulated in the NAcore PSDenriched fraction. These authors used $10 \mathrm{~d}$ of extinction training, whereas we used $21 \mathrm{~d}$, and we showed that the upregulation of PSD-95 and Homer1b/c does not occur after $2 \mathrm{~d}$ of extinction training (Fig. 3D). Other studies also find progressive increases or decreases in protein content at increasing durations of withdrawal from chronic cocaine administration (Bowers et al., 2004; Lu et al., 2005; Conrad et al., 2008).

\section{Consequences of protein changes in the NAshell}

In addition to protein changes in the NAcore, we found decreased GluR2 expression in the NAshell after abstinence but not extinction. Similarly, Sutton et al. (2003) found an increase in GluR2 expression in extinguished animals relative to abstinent animals. We did not observe the significant decrease in GluR1 in the NAshell that has been previously reported (Ghasemzadeh et al., 2009b); however, in both the PSD-enriched (Fig. 1E) and nonPSD (Fig. 2 B) fractions of NAshell tissue from abstinent animals, there was a trend toward a decrease in GluR1 expression. Akin to the upregulation of Homer $1 \mathrm{~b} / \mathrm{c}$ in the NAcore PSD subfraction, a viral overexpression strategy has been used to show that the ability of extinction training to prevent the reduction GluR1 and GluR2 associated with abstinence contributes to the capacity of extinction learning to suppress the reinstatement of cocaine seeking (Sutton et al., 2003). Sutton et al. also reported that overexpressing GluR1 and GluR2 facilitated extinction of the cocaineseeking response. Here, we found that, although overexpression of Homer 1c was able to attenuate reinstatement, it was not able to facilitate extinction learning or prevent abstinent relapse (Fig. $6 B)$. Thus, increased Homer $1 \mathrm{~b} / \mathrm{c}$ expression seems to be a consequence of extinction learning, but does not promote it. The absence of an effect of Homer1c overexpression on abstinent relapse may stem from the fact that the NAcore does not seem to be an essential brain region for the expression of abstinent relapse (See et al., 2007). Extinction training is required to bring this area into the reinstatement neurocircuitry (Peters et al., 2008).

\section{Conclusions}

The present results demonstrate that extinction training after cocaine self-administration induces changes in the expression and/or distribution of Homer1b/c and mGluR5 in the PSD of the NAcore, and the increase in Homer $1 \mathrm{~b} / \mathrm{c}$ expression by extinction training inhibited the induction of LTD. Importantly, these changes were associated with the capacity of extinction training to inhibit cue-induced cocaine seeking. Thus, rather than contributing to cocaine seeking, the upregulated Homer $1 \mathrm{~b} / \mathrm{c}$ and the associated reduced surface expression of mGluR5 and loss of LTD are compensatory adaptations induced by extinction training that reduce cocaine seeking. This marks the Homer-mGluR5 signaling complex as a potential therapeutic target for reducing relapse in cocaine addiction by potentiating learning to inhibit drug seeking.

\section{References}

Andrásfalvy BK, Magee JC (2004) Changes in AMPA receptor currents following LTP induction on rat CA1 pyramidal neurones. J Physiol 559:543-554.

Bachtell RK, Choi KH, Simmons DL, Falcon E, Monteggia LM, Neve RL, Self DW (2008) Role of GluR1 expression in nucleus accumbens neurons in cocaine sensitization and cocaine-seeking behavior. Eur J Neurosci 27:2229-2240.

Bäckström P, Hyytiä P (2006) Ionotropic and metabotropic glutamate receptor antagonism attenuates cue-induced cocaine seeking. Neuropsychopharmacology 31:778-786.

Bowers MS, McFarland K, Lake RW, Peterson YK, Lapish CC, Gregory ML, Lanier SM, Kalivas PW (2004) Activator of G-protein signaling 3: a gatekeeper of cocaine sensitization and drug-seeking. Neuron 42:269-281.

Brebner K, Wong TP, Liu L, Liu Y, Campsall P, Gray S, Phelps L, Phillips AG, Wang YT (2005) Nucleus accumbens long-term depression and the expression of behavioral sensitization. Science 310:1340-1343.

Chiamulera C, Epping-Jordan M, Zocchi A, Marcon C, Cottiny C, Tacconi S, Corsi M, Orzi F, Conquiet F (2001) Reinforcing and locomotor stimulant effects of cocaine are absent in mGluR5 null mutant mice. Nat Neuroscience 4:873-874.

Conklin CA, Tiffany ST (2002) Applying extinction research and theory to cue-exposure addiction treatments. Addiction 97:155-167.

Conrad KL, Tseng KY, Uejima JL, Reimers JM, Heng LJ, Shaham Y, Marinelli M, Wolf ME (2008) Formation of accumbens GluR2-lacking AMPA receptors mediates incubation of cocaine craving. Nature 454:118-121.

Cornish JL, Duffy P, Kalivas PW (1999) A role for nucleus accumbens glutamate transmission in the relapse to cocaine-seeking behavior. Neuroscience 93:1359-1367.

D’Ascenzo M, Fellin T, Terunuma M, Revilla-Sanchez R, Meaney DF, Auberson YP, Moss SJ, Haydon PG (2007) mGluR5 stimulates gliotransmission in the nucleus accumbens. Proc Natl Acad Sci U S A 104:1995-2000.

Di Ciano P, Robbins TW, Everitt BJ (2008) Differential effects of nucleus accumbens core, shell, or dorsal striatal inactivations on the persistence, reacquisition, or reinstatement of responding for a drug-paired conditioned reinforcer. Neuropsychopharmacology 33:1413-1425.

Epstein DH, Preston KL, Stewart J, Shaham Y (2006) Toward a model of drug relapse: an assessment of the validity of the reinstatement procedure. Psychopharmacology (Berl) 189:1-16.

Fagni L, Worley PF, Ango F (2002) Homer as both a scaffold and transduction molecule. Sci STKE 2002:re8.

Fourgeaud L, Mato S, Bouchet D, HémarA, Worley PF, Manzoni OJ (2004) A single in vivo exposure to cocaine abolishes endocannabinoid-mediated long-term depression in the nucleus accumbens. J Neurosci 24:6939-6945.

Fuchs RA, Branham RK, See RE (2006) Different neural substrates mediate cocaine seeking after abstinence versus extinction training: a critical role for the dorsolateral caudate-putamen. J Neurosci 26:3584-3588.

Ghasemzadeh MB, Vasudevan P, Mueller C, Seubert C, Mantsch JR (2009a) Neuroadaptations in the cellular and postsynaptic group 1 metabotropic glutamate receptor mGluR5 and Homer proteins following extinction of cocaine self-administration. Neurosci Lett 452:167-171.

Ghasemzadeh MB, Vasudevan P, Mueller C, Seubert C, Mantsch JR (2009b) Region specific alterations in glutamate receptor expression and subcellular distribution following extinction of cocaine self-administration. Brain Res 1267:89-102.

Goto Y, Grace AA (2005) Dopamine-dependent interactions between limbic and prefrontal cortical plasticity in the nucleus accumbens: disruption by cocaine sensitization. Neuron 47:255-266.

Havermans RC, Jansen AT (2003) Increasing the efficacy of cue exposure treatment in preventing relapse of addictive behavior. Addict Behav 28:989-994.

Kalivas PW, Lalumiere RT, Knackstedt L, Shen H (2009) Glutamate transmission in addiction. Neuropharmacology 56 [Suppl 1]:169-173.

Kammermeier PJ (2006) Surface clustering of metabotropic glutamate receptor 1 induced by long Homer proteins. BMC Neurosci 7:1.

Kauer JA, Malenka RC (2007) Synaptic plasticity and addiction. Nat Rev Neurosci 8:844-858.

Klugmann M, Leichtlein CB, Symes CW, Serikawa T, Young D, During MJ (2005) Restoration of aspartoacylase activity in CNS neurons does not ameliorate motor deficits and demyelination in a model of Canavan disease. Mol Ther 11:745-753.

Kniazeff J, Bessis AS, Maurel D, Ansanay H, Prézeau L, Pin JP (2004) Closed state of both binding domains of homodimeric mGlu receptors is required for full activity. Nat Struct Mol Biol 11:706-713.

Koob GF, Ahmed SH, Boutrel B, Chen SA, Kenny PJ, Markou A, O'Dell LE, Parsons LH, Sanna PP (2004) Neurobiological mechanisms in the tran- 
sition from drug use to drug dependence. Neurosci Biobehav Rev 27:739-749.

Kumaresan V, Yuan M, Yee J, Famous KR, Anderson SM, Schmidt HD, Pierce RC (2009) Metabotropic glutamate receptor 5 (mGluR5) antagonists attenuate cocaine priming- and cue-induced reinstatement of cocaine seeking. Behav Brain Res 202:238-244.

Lu L, Hope BT, Dempsey J, Liu SY, Bossert JM, Shaham Y (2005) Central amygdala ERK signaling pathway is critical to incubation of cocaine craving. Nat Neurosci 8:212-219.

Madayag A, Lobner D, Kau KS, Mantsch JR, Abdulhameed O, Hearing M, Grier MD, Baker DA (2007) Repeated $N$-acetylcysteine administration alters plasticity-dependent effects of cocaine. J Neurosci 27:13968-13976.

Malenka RC, Bear MF (2004) LTP and LTD: an embarrassment of riches. Neuron 44:5-21.

Mao L, Yang L, Tang Q, Samdani S, Zhang G, Wang JQ (2005) The scaffold protein Homer $1 \mathrm{~b} / \mathrm{c}$ links metabotropic glutamate receptor 5 to extracellular signal-regulated protein kinase cascades in neurons. J Neurosci 25:2741-2752.

Martin M, Chen BT, Hopf FW, Bowers MS, Bonci A (2006) Cocaine selfadministration selectively abolishes LTD in the core of the nucleus accumbens. Nat Neurosci 9:868-869.

Migaud M, Charlesworth P, Dempster M, Webster LC, Watabe AM, Makhinson M, He Y, Ramsay MF, Morris RG, Morrison JH, O'Dell TJ, Grant SG (1998) Enhanced long-term potentiation and impaired learning in mice with mutant postsynaptic density-95 protein. Nature 396:433-439.

Milliken GA, Johnson DE (1984) Analysis of messy data, Vol I, Designed experiments. Belmont, CA: Lifetime Learning Publications.

Moussawi K, Pacchioni A, Moran M, Olive MF, Gass JT, Lavin A, Kalivas PW (2009) N-Acetylcysteine reverses cocaine-induced metaplasticity. Nat Neurosci 12:182-189.

O’Brien C (2001) Drug addiction and drug abuse. In: The pharmacological basis of therapeutics (Hardman JG, Limbird LE, Gilman AG, eds), pp 621-642. New York: McGraw-Hill.

Olive MF, McGeehan AJ, Kinder JR, McMahon T, Hodge CW, Janak PH, Messing RO (2005) The mGluR5 antagonist 6-methyl-2-(phenylethynyl) pyridine decreases ethanol consumption via a protein kinase $\mathrm{C}$ epsilondependent mechanism. Mol Pharmacol 67:349-355.

Park WK, Bari AA, Jey AR, Anderson SM, Spealman RD, Rowlett JK, Pierce RC (2002) Cocaine administered into the medial prefrontal cortex reinstates cocaine-seeking behavior by increasing AMPA receptor-mediated glutamate transmission in the nucleus accumbens. J Neurosci 22:29162925.

Paxinos G, Watson C (1986) The rat brain in stereotaxic coordinates, Ed 2. New York: Academic.

Peters J, LaLumiere RT, Kalivas PW (2008) Infralimbic prefrontal cortex is responsible for inhibiting cocaine seeking in extinguished rats. J Neurosci 28:6046-6053.

Peters J, Kalivas PW, Quirk GJ (2009) Extinction circuits for fear and addiction overlap in prefrontal cortex. Learn Mem 16:279-288.
Pin JP, Galvez T, Prézeau L (2003) Evolution, structure, and activation mechanism of family $3 / \mathrm{C}$ G-protein-coupled receptors. Pharmacol Ther 98:325-354.

Quirk GJ, Mueller D (2008) Neural mechanisms of extinction learning and retrieval. Neuropsychopharmacology 33:56-72.

Robbe D, Kopf M, Remaury A, Bockaert J, Manzoni OJ (2002) Endogenous cannabinoids mediate long-term synaptic depression in the nucleus accumbens. Proc Natl Acad Sci U S A 99:8384-8388.

Ronesi JA, Huber KM (2008) Homer interactions are necessary for metabotropic glutamate receptor-induced long-term depression and translational activation. J Neurosci 28:543-547.

See RE, Elliott JC, Feltenstein MW (2007) The role of dorsal vs ventral striatal pathways in cocaine-seeking behavior after prolonged abstinence in rats. Psychopharmacology (Berl) 194:321-331.

Self DW, Choi KH, Simmons D, Walker JR, Smagula CS (2004) Extinction training regulates neuroadaptive responses to withdrawal from chronic cocaine self-administration. Learn Mem 11:648-657.

Sutton MA, Schmidt EF, Choi KH, Schad CA, Whisler K, Simmons D, Karanian DA, Monteggia LM, Neve RL, Self DW (2003) Extinction-induced upregulation in AMPA receptors reduces cocaine-seeking behaviour. $\mathrm{Na}$ ture 421:70-75.

Szumlinski KK, Dehoff MH, Kang SH, Frys KA, Lominac KD, Klugmann M, Rohrer J, Griffin W 3rd, Toda S, Champtiaux NP, Berry T, Tu JC, Shealy SE, During MJ, Middaugh LD, Worley PF, Kalivas PW (2004) Homer proteins regulate sensitivity to cocaine. Neuron 43:401-413.

Szumlinski KK, Abernathy KE, Oleson EB, Klugmann M, Lominac KD, He DY, Ron D, During M, Kalivas PW (2006) Homer isoforms differentially regulate cocaine-induced neuroplasticity. Neuropsychopharmacology 31:768-777.

Tateyama M, Abe H, Nakata H, Saito O, Kubo Y (2004) Ligand-induced rearrangement of the dimeric metabotropic glutamate receptor 1alpha. Nat Struct Mol Biol 11:637-642.

Wibrand K, Messaoudi E, Håvik B, Steenslid V, Løvlie R, Steen VM, Bramham CR (2006) Identification of genes co-upregulated with Arc during BDNF-induced long-term potentiation in adult rat dentate gyrus in vivo. Eur J Neurosci 23:1501-1511.

Xiao B, Tu JC, Petralia RS, Yuan JP, Doan A, Breder CD, Ruggiero A, Lanahan AA, Wenthold RJ, Worley PF (1998) Homer regulates the association of group 1 metabotropic glutamate receptors with multivalent complexes of homer-related, synaptic proteins. Neuron 21:707-716.

Xu D, Hopf C, Reddy R, Cho RW, Guo L, Lanahan A, Petralia RS, Wenthold RJ, O’Brien RJ, Worley P (2003) Narp and NP1 form heterocomplexes that function in developmental and activity-dependent synaptic plasticity. Neuron 39:513-528.

Yao WD, Gainetdinov RR, Arbuckle MI, Sotnikova TD, Cyr M, Beaulieu JM, Torres GE, Grant SG, Caron MG (2004) Identification of PSD-95 as a regulator of dopamine-mediated synaptic and behavioral plasticity. Neuron 41:625-638. 